\title{
VOLUME LALU LINTAS DAN LEVEL OF SERVICE (LOS) DI KORIDOR JALAN GAJAH MADA KOTA PONTIANAK
}

\author{
Arghifa Fitri Sulistya Farhandi ${ }^{1}$, Ely Nurhidayati ${ }^{2}$, Meta Indah Fitriani ${ }^{3}$
}

1,2,3 Jurusan Perencanaan Wilayah dan Kota Fakultas Teknik Universitas Tanjungpura

1Email:arghifa@gmail.com

\begin{abstract}
The trade and service sector is one of the most important factors, and this needs to be considered because the trade and service sector plays a very important role in regional economic development. Transportation facilities and infrastructure are mutually supportive factors and both in the transportation system are the main requirements. Transportation facilities related to traffic are terminals, traffic signs and markings, pedestrian facilities, parking facilities and places to stop. The purpose of this study was to identify the characteristics and number of trade and service buildings, modes of transportation and parking lots and to identify traffic volume and LOS in the Gajah Mada Road Corridor, Pontianak City. This research method is a quantitative method with descriptive analysis techniques, traffic counting and volume capacity ratio. Trade on Gajah Mada Road is still traded in retail with shops as the most common form of trade and primary commodities, the level of tangibles dominates services, there are three categories of transportation modes with parking space determined by the building area. The results of VCR and LOS varied with values of 0.1-0.3 and LOS A-B ranges on the three days and times.
\end{abstract}

Keywords: traffic, trade and services, transportation

\begin{abstract}
ABSTRAK
Sektor perdagangan dan jasa merupakan salah satu faktor terpenting, dan hal ini perlu diperhatikan karena sektor perdagangan dan jasa sangat berperan dalam pembangunan ekonomi daerah. Sarana dan prasaran transportasi merupakan faktor yang berhubungan dan syarat utama dalam sistem transportasi. Sarana transportasi dirancang untuk mendukung masyarakat dengan tujuan mobilitas. Adapun fasilitas lalu lintas seperti rambu dan marka lalu lintas, fasilitas parkir dan tempat parkir. Tujuan dari penelitian ini adalah untuk mengidentifikasi karakteristik dan jumlah bangunan perdagangan dan jasa, moda transportasi serta lahan parkir dan mengidentifkasi volume lalu lintas dan LOS di Koridor Jalan Gajah Mada Kota Pontianak. Metode penelitian ini adalah metode kuantitatif dengan teknik analisis deskriptif, traffic counting dan rasio kapasitas volume. Perdagangan di Jalan Gajah Mada masih diperjual belikan secara eceran dengan pertokoan sebagai bentuk perdagangan yang banyak dijumpai serta komoditas primer, kategori tingkat keberwujudan mendominasi jasa, terdapat tiga kategori moda transportasi dengan lahan parkir yang ditentukan oleh luas bangunan. Hasil VCR dan LOS yang bervariasi dengan nilai 0,1-0,3 dan rentang LOS A-B pada ketiga hari dan waktu.
\end{abstract}

Kata kunci: lalu lintas, perdagangan dan jasa, transportasi 


\section{PENDAHULUAN}

Kegiatan perdagangan dan jasa berkaitan erat dengan perkembangan kota. Sektor perdagangan dan jasa merupakan salah satu faktor terpenting dan hal ini perlu diperhatikan karena sektor perdagangan dan jasa sangat berperan dalam pembangunan ekonomi daerah dan manfaat yang dihasilkan secara langsung melalui peluang usaha dan kesempatan kerja di daerah. Sarana dan prasaran transportasi merupakan faktor yang berhubungan dan syarat utama dalam sistem transportasi. Sarana transportasi dirancang untuk mendukung masyarakat dengan tujuan mobilitas. Adapun fasilitas lalu lintas seperti rambu dan marka lalu lintas, fasilitas parkir dan tempat parkir.

Jalan Gajah Mada merupakan jalan yang mempunyai arus lalu lintas yang besar, karena merupakan kawasan Pusat Pelayanan Kota serta sebagai salah satu pusat perekonomian di Kota Pontianak dengan ini pula status jalannya yakni jalan arteri sekunder. (Rencana Tata Ruang Wilayah Kota Pontianak Tahun 2013-2033). Sesuai dengan fungsinya, terdapat pendidikan menengah-tinggi dan pelayanan skala regional.

Pada Jalan Gajah Mada sendiri permasalahan transportasi yang terjadi biasanya seperti kemacetan yang terjadi pada titik putar arah yang ada dibeberapa titik di Jalan Gajah Mada. Kemacetan ini terjadi dikarenakan adanya penyempitan lajur yang berdekatan dengan titik putar arah karena digunakan untuk memarkirkan kendaraan. Jalan Gajah Mada sendiri belum memiliki fasilitas parkir yang kendaraan yang layak, karena masih terdapat kendaraan yang parkir di bahu jalan dikarenakan kurangnya lahan parkir dan masih terdapat pengendara yang melawan arah.

Berdasarkan hal tersebut, maka tujuan penelitian ini adalah untuk mengidentifikasi karakteristik dan jumlah perdagangan dan jasa, moda transportasi, lahan parkir serta mengidentifikasi volume lalu lintas dan LOS di Jalan Gajah Mada.

\section{METODOLOGI}

Lokasi penelitian yakni di koridor Jalan Gajah Mada yang berada dalam Kecamatan Pontianak Selatan, Kota Pontianak dan dilakukan pada tahun 2020. Penelitian ini menggunakan metode kuantitatif, dengan tujuan untuk menganalisis hasil kuesioner dari karakteristik perdagangan dan jasa, moda transportasi dan lahan parkir di koridor Jalan Gajah Mada. 
Penelitian ini bertujuan untuk mengidentifikasi karakteristik dan jumlah perdagangan dan jasa, moda transportasi, lahan parkir serta volume lalu lintas dan LOS di Jalan Gajah Mada.

Adapun yang menjadi populasi dalam penelitian ini adalah jumlah penduduk Kota Pontianak Tahun 2019 dengan jumlah 646.661 jiwa dan koridor Jalan Gajah Mada dengan panjang $\pm 1500 \mathrm{~m}$. Sampel yang digunakan adalah orang yang bekerja dibangunan tersebut yang mana untuk merepresentasikan karakteristik bangunan perdagangan dan jasa serta 3 segmen dengan 8 titik traffic counting pada dua jalur di Jalan Gajah Mada dengan panjang segmen \pm 500 $\mathrm{m}$. Penelitian ini menggunakan purposive sampling, yaitu teknik pengambilan sampel dengan menentukan kriteria-kriteria tertentu, dimana karakteristik perdagangan dan jasa. Perhitungan sampel menggunakan rumus slovin dengan tingkat kesalahan 10\%. Jadi, sampel penelitian yang didapat adalah 100 responden. Untuk traffic counting dilakukan selama tiga hari, yaitu kamis, sabtu dan minggu dengan tiga waktu pada pagi pukul 08.00-09.00, siang pukul 12.00-13.00 dan sore pukul 16.00-17.00.

\section{A. Teknik Pengumpulan Data}

Teknik pengumpulan data penelitian ini adalah dengan penyebaran kuesioner dan traffic counting yang dilakukan di koridor Jalan Gajah Mada. Data sekunder berupa studi literatur digunakan untuk mendapatkan data-data terkait perdagangan dan jasa dan data sekuner lainnya dapat berasal dari instansi terkait atau berupa peraturan atau pedoman yang berlaku untuk kebutuhan data. Observasi dilakukan untuk meninjau lokasi penelitian di Jalan Gajah Mada. Selain observasi, penelitian ini menggunakan data sekunder dari Dinas Koperasi, Usaha Mikro dan Perdagangan Kota Pontianak, Dinas Pariwisata Kota Pontianak dan Badan Pusat Statistik Kota Pontianak.

\section{B. Variabel Penelitian}

Berikut adalah variabel yang digunakan dalam penelitian ini, yang dapat dilihat pada tabel 1.

Tabel 1. Variabel Penelitian

\begin{tabular}{|c|c|c|c|}
\hline Sasaran & Variabel & Indikator & Parameter \\
\hline $\begin{array}{l}\text { Mengidentifikasi } \\
\text { karakteristik dan }\end{array}$ & & $\begin{array}{l}\text { Berdasarkan volume } \\
\text { barang yang dijual }\end{array}$ & - Grosir \\
\hline $\begin{array}{l}\text { jumlah bangunan } \\
\text { perdagangan dan jasa }\end{array}$ & Jen1s & $\begin{array}{l}\text { Berdasarkan cara } \\
\text { distribusi barang }\end{array}$ & $\begin{array}{l}\text { - Pembeli ke pedagang } \\
\text { - Pedagang ke pembeli }\end{array}$ \\
\hline
\end{tabular}




\begin{tabular}{|c|c|c|c|}
\hline Sasaran & Variabel & Indikator & Parameter \\
\hline \multirow[t]{11}{*}{$\begin{array}{l}\text { serta karakteristik } \\
\text { moda transportasi serta } \\
\text { lahan parkir }\end{array}$} & & $\begin{array}{l}\text { Berdasarkan bentuk } \\
\text { tempat perdagangan }\end{array}$ & $\begin{array}{ll}\text { - } & \text { Pasar tradisional } \\
\text { - } & \text { Toko modern } \\
\text { - } & \text { Warung toko } \\
\text { - } & \text { Pertokoan } \\
\text { - } & \text { Boutique } \\
\end{array}$ \\
\hline & & $\begin{array}{l}\text { Berdasarkan komoditas } \\
\text { yang dijual }\end{array}$ & $\begin{array}{ll}\text { - } & \text { Primer } \\
\text { - } & \text { Sekunder } \\
\text { - } & \text { Tersier } \\
\end{array}$ \\
\hline & \multirow{7}{*}{ Jenis jasa } & Segmen Pasar & $\begin{array}{l}\text { - Jasa yang ditujukan } \\
\text { pada konsumen } \\
\text { - Jasa bagi konsumen }\end{array}$ \\
\hline & & Tingkat keberwujudan & $\begin{array}{l}\text { - } \quad \text { Rented-good services } \\
\text { - Owned-good services } \\
\text { - Non-good services }\end{array}$ \\
\hline & & $\begin{array}{l}\text { Keterampilan penyedia } \\
\text { jasa }\end{array}$ & \begin{tabular}{|l} 
- $\begin{array}{l}\text { Profesional services } \\
\text { - Non-profesional } \\
\text { services }\end{array}$ \\
\end{tabular} \\
\hline & & $\begin{array}{l}\text { Tujuan organisasi } \\
\text { penyedia jasa }\end{array}$ & $\begin{array}{l}\text { - Commercial services } \\
\text { - Non-profit services }\end{array}$ \\
\hline & & Regulasi & 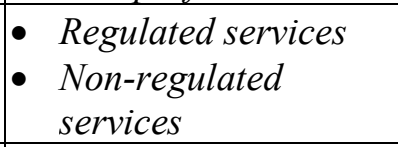 \\
\hline & & $\begin{array}{l}\text { Tingkat intensitas } \\
\text { karyawan }\end{array}$ & \begin{tabular}{|l} 
- $\begin{array}{l}\text { Equipment-based } \\
\text { services }\end{array}$ \\
- People-based \\
services
\end{tabular} \\
\hline & & $\begin{array}{l}\text { Tingkat kontak penyedia } \\
\text { jasa dan pelayanan }\end{array}$ & $\begin{array}{ll}\text { - } & \text { High-contact } \\
\text { services } \\
\text { - }\end{array}$ \\
\hline & Moda Transportasi & & $\begin{array}{ll}\text { - } & \text { Heavy Vehicle } \\
\text { - Light Vehicle } \\
\text { - } \text { Motorcycle } \\
\end{array}$ \\
\hline & Lahan parkir & $\begin{array}{l}\text { Area atau ruang yang } \\
\text { dapat digunakan untuk } \\
\text { kepentingan parkir } \\
\text { kendaraan }\end{array}$ & $\begin{array}{ll}\text { - } & \text { Ada lahan parkir } \\
\text { - } & \text { Tidak ada lahan } \\
\text { parkir }\end{array}$ \\
\hline \multirow{2}{*}{$\begin{array}{l}\text { Mengidentifikasi } \\
\text { volume dan arus lalu } \\
\text { lintas yang ada di } \\
\text { koridor Jalan Gajah } \\
\text { Mada }\end{array}$} & Volume kendaraan & 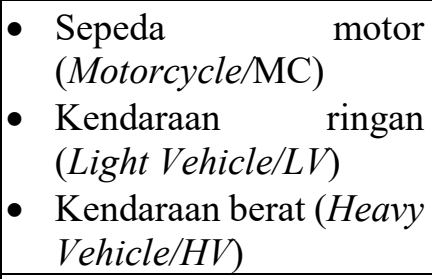 & $\begin{array}{l}\text { Kendaraan yang } \\
\text { melewati ruas jalan } \\
\text { yang diamati dalam } \\
\text { interval waktu tertentu }\end{array}$ \\
\hline & Kapasitas & $\begin{array}{l}\text { Arus lalu lintas } \\
\text { maksimum yang dapat } \\
\text { dipertahankan melalui } \\
\text { titik jalan dalam suatu } \\
\end{array}$ & $\begin{array}{l}\text { - Kapasitas ruas jalan } \\
\text { (C) } \\
\text { - Kapasitas dasar }\left(\mathrm{C}_{\mathrm{o}}\right)\end{array}$ \\
\hline
\end{tabular}




\begin{tabular}{|c|c|c|c|}
\hline Sasaran & Variabel & Indikator & Parameter \\
\hline & & $\begin{array}{l}\text { keadaan tertentu per } \\
\text { satuan jam }\end{array}$ & $\begin{array}{llr}\text { - } & \text { Faktor } & \text { penyesuaian } \\
\text { kapasitas } & \text { untuk lebar } \\
& \text { jalur lalu-lintas }\left(\mathrm{FC}_{\mathrm{w}}\right) \\
\text { - } & \text { Faktor penyesuaian } \\
& \text { kapasitas } & \text { untuk } \\
\text { pemisahan } & \text { arah } \\
\left(\mathrm{FC}_{\mathrm{sp}}\right) & \\
\text { - } & \text { Faktor } & \text { penyesuaian } \\
& \text { kapasitas } & \text { untuk } \\
& \text { hambatan } & \text { samping } \\
& \left(\mathrm{FC}_{\mathrm{sf}}\right) & \\
\text { - } & \text { Faktor } & \text { penyesuaian } \\
& \text { kapasitas } & \text { untuk } \\
& \text { ukuran kota } & \left(\mathrm{FC}_{\mathrm{cs}}\right)\end{array}$ \\
\hline & $\begin{array}{l}\text { Derajat } \\
\text { kejenuhan/VCR }\end{array}$ & $\begin{array}{l}\text { Rasio arus lalu lintas } \\
\text { (smp/jam) terhadap } \\
\text { kapasitas (smp/jam) pada } \\
\text { bagian jalan tertentu. }\end{array}$ & 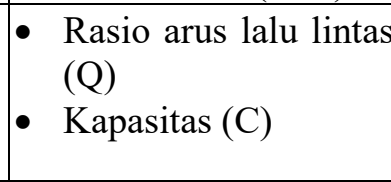 \\
\hline
\end{tabular}

Sumber: Penulis, 2021

\section{Teknik Analisis}

Adapun teknik analisis yang digunakan, yaitu:

\section{Analisis Deskriptif}

Suatu metode untuk menggambarkan atau memberikan gambaran tentang objek penelitian melalui informasi yang terkumpul, tanpa perlu menganalisis dan menarik kesimpulan yang berlaku umum (Sugiyono, 2016).

\section{Analisis Traffic Counting}

Besarnya pergerakan terlihat dari banyaknya kendaraan yang melintas di jalan raya dalam kurun waktu tertentu.

\section{Analisis Volume Capacity Ratio}

Volume lalu lintas jalan mengacu pada jumlah atau jumlah kendaraan yang melewati suatu titik tertentu di jalan dalam satu satuan waktu pada jam-jam tersibuk dalam sehari (MKJI, 1997).

\section{Analisis Level Of Service}

Kinerja Jalan USHCM atau Tingkat Layanan adalah indikator kualitatif yang digunakan di Amerika Serikat yang menggambarkan kondisi lalu lintas operasional dan peringkat 
pengguna jalan. Dinyatakan dalam kecepatan, waktu tempuh, kebebasan bergerak, kemacetan lalu lintas, kemudahan, kenyamanan dan keamanan (MKJI, 1997).

\section{HASIL DAN PEMBAHASAN}

\section{A. Gambaran Umum}

Kota Pontianak merupakan Ibukota Provinsi Kalimantan Barat. Jumlah penduduk Kota Pontianak pada tahun 2020 diperkirakan sebanyak 658.685 jiwa (BPS Kota Pontianak, 2021). Kota Pontianak terdiri dari 6 kecamatan, yaitu Kecamatan Pontianak Barat, Pontianak Selatan, Pontianak Tenggara, Pontianak Kota, Pontianak Timur dan Pontianak Utara. Lokasi penelitian, Jalan Gajah Mada terletak di Kecamatan Pontianak Selatan. Luas Kecamatan Pontianak Selatan adalah $16,52 \mathrm{~km}^{2}$. Berikut ini adalah peta dan batas - batas untuk Kecamatan Pontianak Selatan, yang dapat dilihat pada gambar 1.

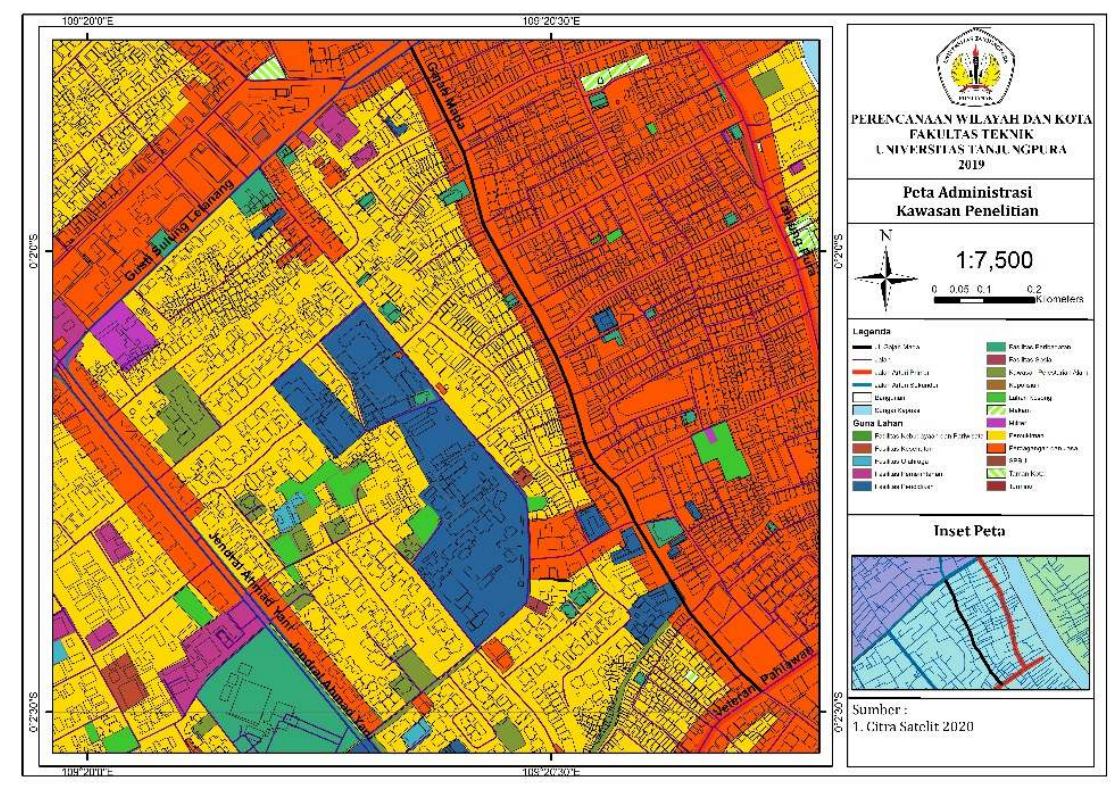

\section{Gambar 1. Peta Lokasi Penelitian}

Sumber: Penulis, 2021

Batas kawasan studi

Utara : Kecamatan Pontianak Utara

Selatan: Kecamatan Pontianak Tenggara

Timur : Kecamatan Pontianak Timur

Barat : Kecamatan Sungai Kakap 
Lingkup wilayah dalam studi ini meliputi koridor Jalan Gajah Mada. Apabila dilihat pada Rencana Tata Ruang Wilayah Kota Pontianak tahun 2013-2033, kawasan Jalan Gajah Mada merupakan jalan yang mempunyai arus lalu lintas yang besar, karena merupakan kawasan Pusat Pelayanan Kota serta sebagai salah satu pusat perekonomian di Kota Pontianak.

Jalan Gajah Mada memiliki kondisi geometric, yaitu tipe jalan empat lajur terbagi atau 4/2 D. Pada Jalan Gajah Mada sendiri memiliki panjang $\pm 1500 \mathrm{~m}$ dengan lebar jalan yang bervariasi di beberapa titik antara 6-7,5 m. Pada Jalan Gajah Mada sendiri terdapat median jalan dengan nilai pemisah arah 50-50, dimana nilai pemisah arah disini berdasarkan ketentuan Manual Kapasitas Jalan Indonesia.

\section{B. Karakteristik dan Jumlah Bangunan Perdagangan dan Jasa, Moda Transportasi serta Lahan Parkir}

Jalan Gajah Mada merupakan salah satu jalan yang memiliki aktivitas yag kompleks dikarenakan Jalan Gajah Mada merupakan daerah perdagangan dan jasa di Kota Pontianak. Dari perkembangan perdagangan dan jasa yang semakin pesat, harus di imbangi dengan keberadaan lahan parkir. Kebutuhan lahan parkir saat ini sangat penting dimana beberapa kegiatan perdagangan dan jasa yang ada di Jalan Gajah Mada masih belum memiliki kebutuhan lakan parkir yang memadai. Hal ini diikuti dengan banyaknya jumlah moda transportasi yang melewati Jalan Gajah Mada. Dari penjelasan ini, berikut hasil analisis karakteristik dan jumlah bangunan perdagangan dan jasa, moda transportasi serta lahan parkir:

1) Perdagangan dan Jasa

Kegiatan perdagangan yang diklasifikasikan berdasarkan volume barang yang dijual, bentuk tempat, jenis komoditas yang dijual, cara transaksi barang, dan lain-lain.

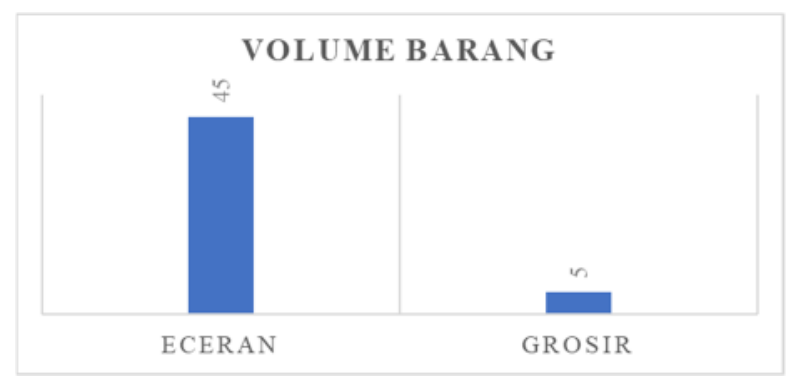

(a)

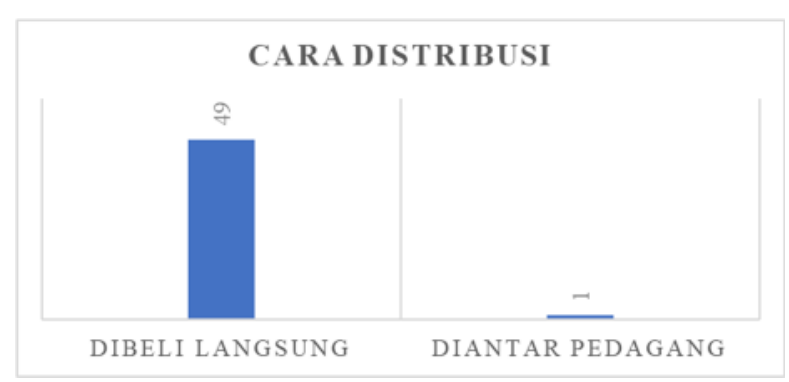

(b)

Gambar 2. Jumlah Perdagangan (a) berdasarkan volume barang; (b) berdasarkan cara distribusi

Sumber: Hasil Analisis, 2021 
Berdasarkan gambar 2, untuk perdagangan berdasarkan volume barang dapat dilihat pada gambar 2 (a) sebagian besar barang yang dijual secara eceran dengan 45 responden dan 5 responden yang menjual barang secara grosir. Selanjutnya berdasarkan cara distribusi barang pada gambar 2 (b) hampir semua responden menjawab barang yang diperjual belikan dibeli langsung oleh konsumen.

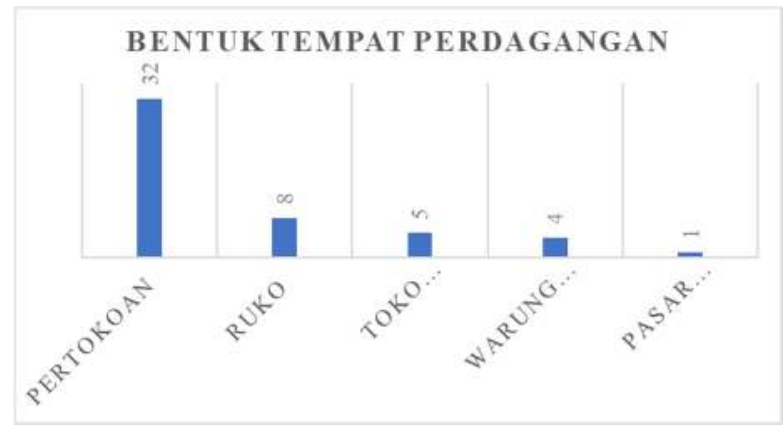

(a)

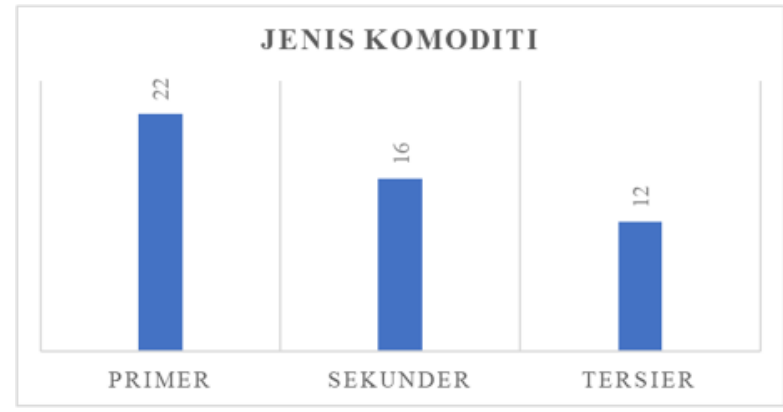

(b)

Gambar 3. Jumlah Perdagangan (a) berdasarkan bentuk tempat perdagangan; (b) berdasarkan komoditas

Sumber: Hasil Analisis, 2021

Berdasarkan gambar 3 (a), untuk tempat perdagangan, terdapat lima jenis bentuk tempat perdagangan, adapun pertokoan adalah bentuk tempat perdagangan yang banyak di koridor Jalan Gajah Mada, dengan sisanya adalah ruko, toko modern, warung toko dan pasar tradisional. Pada gambar 3 (b), didapatkan bahwa komoditas primer cukup banyak diperjual belikan di Jalan Gajah Mada, diikuti dengan komiditas sekunder dan tersier.

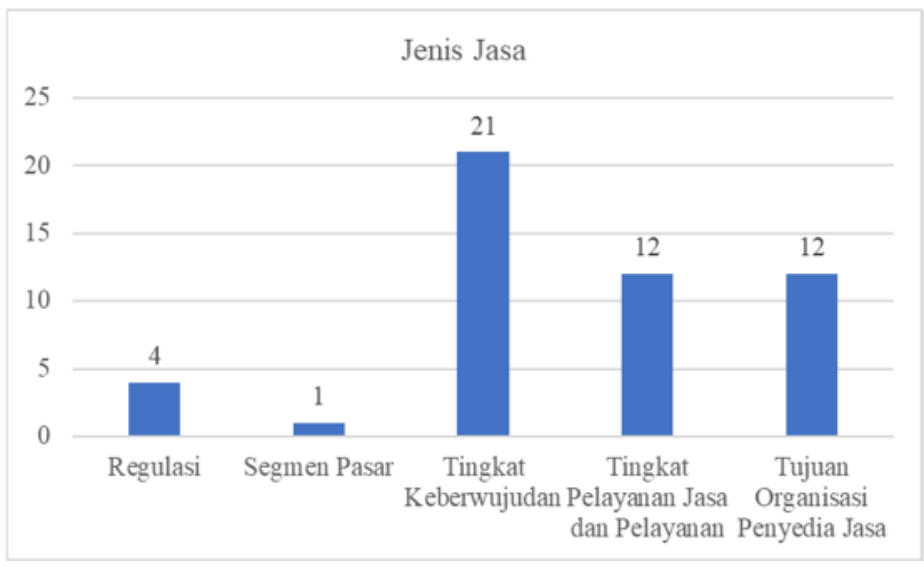

Gambar 4. Jumlah Jasa Berdasarkan Jenis Jasa

Sumber: Hasil Analisis, 2021 
Berdasarkan gambar 2, bahwa di Jalan Gajah Mada terdapat lima kategori jasa, yaitu regulasi, segmen pasar, tingkat keberwujudan, tingkat kontak penyedia jasa dan pelayanan serta tujuan organisasi penyedia jasa. Kategori tingkat keberwujudan mendominasi kategori jasa di Jalan Gajah Mada, berupa bengkel/dealer mobil dan motor, pemandu wisata dan toko computer. Selanjutnya adalah kategori tingkat kontak penyedia jasa berupa bank dan jasa layanan pos. Tujuan organisasi penyedia jasa berupa hotel dan kategori regulasi berupa media massa dan makelar serta untuk kategori terakhir adalah segmen pasar berupa pendidikan.

2) Moda Transportasi

Berdasarkan hasil traffic counting yang dilakukan, moda transportasi yang digunakan di koridor Jalan Gajah Mada dapat dikategorikan menjadi tiga, yaitu kendaraan berat, ringan dan motor yang dapat dilihat pada tabel 2.

Tabel 2. Kategori Kendaraan

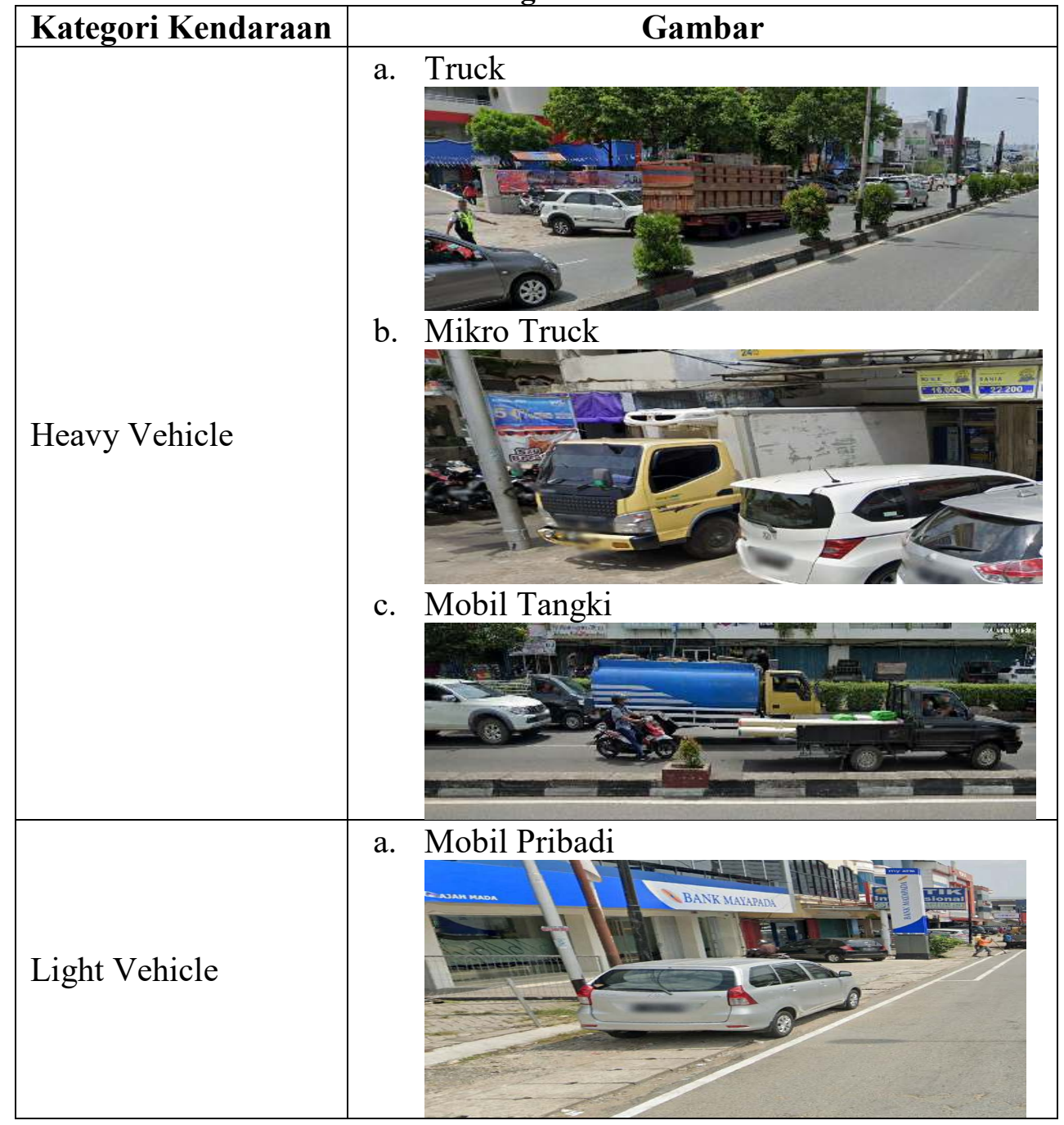




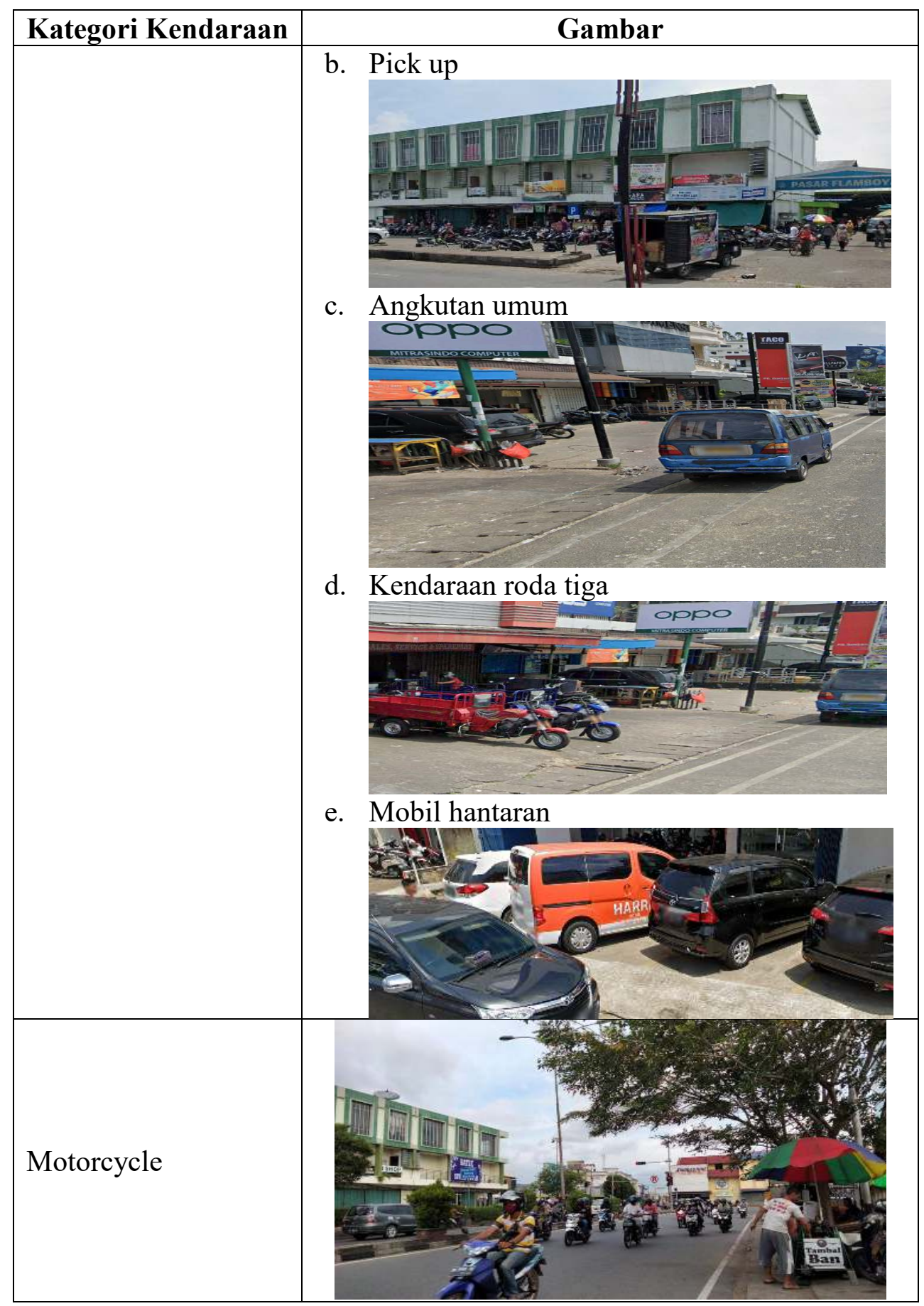




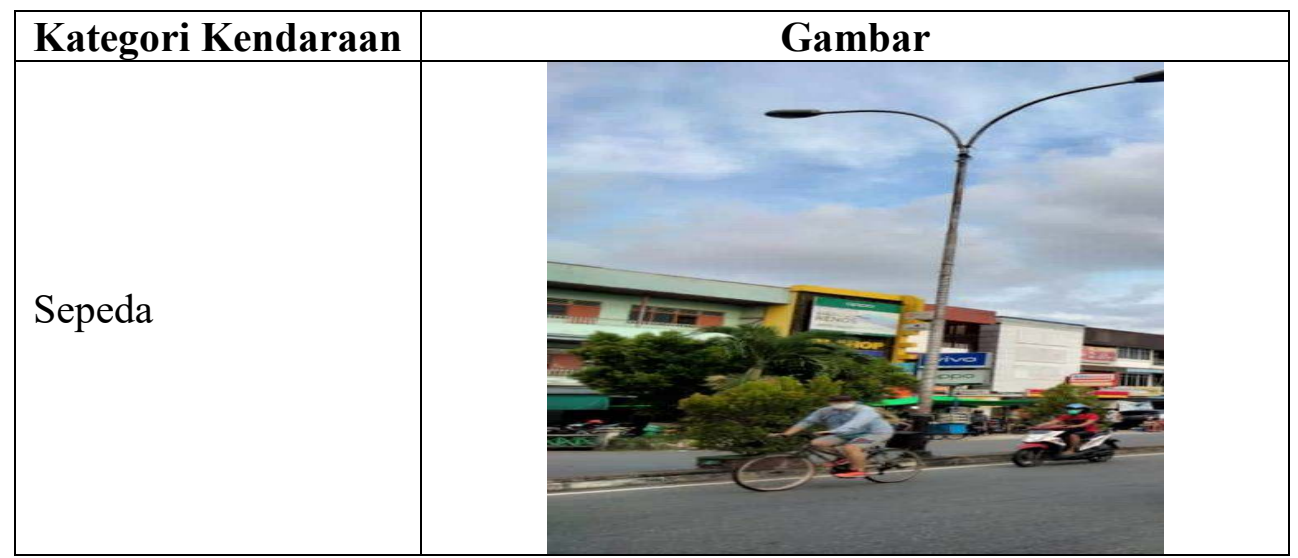

Sumber: Hasil Analisis, 2021

3) Lahan Parkir

Pada koridor Jalan Gajah Mada lahan parkir ditentukan dengan seberapa luas bangunannya. Pada bangunan yang memiliki luas cukup besar menyediakan lahan parkir yang cukup banyak bagi kendaraan yang akan memarkirkan kendaraannya, sebaliknya pada bangunan yang memiliki luas yang tidak besar menyediakan lahan parkir yang tidak seberapa dan hanya cukup untuk beberapa motor dan mobil saja, serta jika lahan parkir sudah penuh atau tidak tersedia maka terdapat kendaraan yang memarkirkan kendaraannya di badan jalan. Sebagian besar, parkir yang disediakan hanya berkisar untuk 10-20 motor dan beberapa mobil saja. parkir yang terdapat pada bangunan perdagangan dan jasa di Jalan Gajah Mada hanya beberapa bangunan saja yang memenuhi SRP parkir yang sesuai dengan Pedoman Perencanaan dan Pengoperasian Fasilitas Parkir Tahun 1998, adapun bangunan yang memenuhi SRP tersebut, yaitu Pasar Flamboyan, Hotel Grand, Hotel Aston, Hotel Queen dan Hotel 2000. Sedangkan bangunan perdagangan dan jasa yang lainnya terdapat beberapa yang tidak memenuhi dan banyak juga yang tidak terdapat didalam pedoman sehingga tidak bisa dikatakan memenuhi standar atau tidak.

\section{Volume Lalu Lintas dan Level Of Service (LOS) di Koridor Jalan Gajah Mada}

Adapun dalam menghitung volume dan arus lalu lintas, hasil dari perhitungan tersebut akan menentukan tingkat pelayanan dari suatu jalan, yang mana jalan itu akan masuk ke ketegori bebas hambatan rendah, sedang dan tinggi atau macet sesuai dengan tingkatan pelayanannya. Berikut adalah kapasitas dari masing-masing ruas jalan: 
Tabel 3. Kapasitas Jalan 1

\begin{tabular}{|c|l|l|r|}
\hline No & \multicolumn{1}{|c|}{ Parameter } & \multicolumn{1}{|c|}{ Kondisi } & Nilai \\
\hline 1 & Kapasitas Dasar (Co) & Dua jalur tidak terpisah & 3300 \\
\hline 2 & Faktor Penyesuaian Lebar Jalur Lalu Lintas (Fcw) & $14(7)$ & 1.00 \\
\hline 3 & Faktor Penyesuaian Pemisahan Arah (Fcsp) & Dua arah & 1.00 \\
\hline 4 & Faktor Penyesuaian Hambatan Samping (Fcsf) & Daerah komersial tinggi & 0.98 \\
\hline 5 & Faktor Penyesuaian Ukuran Kota (Fccs) & 646661 & 0.94 \\
\hline
\end{tabular}

Sumber: Hasil Analisis, 2021

Tabel 4. Kapasitas Jalan 2

\begin{tabular}{|c|l|l|r|}
\hline No & \multicolumn{1}{|c|}{ Parameter } & \multicolumn{1}{|c|}{ Kondisi } & Nilai \\
\hline 1 & Kapasitas Dasar (Co) & Dua jalur tidak terpisah & 3300 \\
\hline 2 & Faktor Penyesuaian Lebar Jalur Lalu Lintas (Fcw) & $14(7)$ & 1.00 \\
\hline 3 & Faktor Penyesuaian Pemisahan Arah (Fcsp) & Dua arah & 1.00 \\
\hline 4 & Faktor Penyesuaian Hambatan Samping (Fcsf) & Pasar & 0.95 \\
\hline 5 & Faktor Penyesuaian Ukuran Kota (Fccs) & 646661 & 0.94 \\
\hline
\end{tabular}

Sumber: Hasil Analisis, 2021

Dapat dilihat yang membedakan tabel 3 dan 4 adalah pada bagian faktor penyesuaian hambatan samping, dimana pada tabel 3 kondisi untuk hambatan sampingnya adalah daerah komersial tinggi dan pada tabel 4 kondisi hambatan sampingnya adalah pasar. Berdasarkan perbedaan hambatan samping tersebut, maka penggunaan perhitungan untuk tabel 3 dilakukan pada titik $1 \mathrm{~A}, 2 \mathrm{AB}, 3 \mathrm{AB}$ dan $4 \mathrm{AB}$, sedangkan perhitungan menggunakan tabel 4 hanya dilakukan pada titik 1B dikarenakan titik ini berdekatan dengan Pasar Flamboyan.

Berdasarkan hasil analisis, koridor Jalan Gajah Mada memiliki nilai kapasitas dasar 3300, faktor lebar jalan 1,00, faktor pemisah arah 1,00, faktor hambatan samping 0,98 dan 0,95 serta faktor ukuran kota 0,94. Dengan nilai - nilai tersebut dilakukan analisis dan didapatkan nilai VCR dan LOS pada Jalan Gajah Mada. Hasil analisis menunjukan bahwa Jalan Gajah Mada memiliki nilai VCR yang bervariasi dengan nilai VCR paling besar 0,3636 pada hari sabtu sore dan nilai VCR paling kecil 0,1419 pada hari minggu pagi. Pada hari sabtu baik dari waktu pagi hingga sore, memiliki LOS sebagian besar B dikarenakan pada hari tersebut banyak kendaraan yang melewati Jalan Gajah Mada dengan intensitas sangat banyak dan didominasi oleh kendaraan pribadi seperti motor dan mobil pribadi. Sedangkan, untuk hari kamis dan minggu nilai VCR dan LOS pada ketiga waktu masih bervariasi. Nilai VCR keseluruhan 
berkisar dari 0,1-0,3 dan LOS pada tiap segmen dari ketiga hari tersebut juga berada antara A dan B, yang artinya Jalan Gajah Mada masih aman dari kemacetan dan hanya terjadi hambatan kecepatan kendaran dikarenakan ada beberapa titik untuk melakukan putar arah dan terdapat beberapa akses untuk menuju Jalan Gajah Mada.

\section{KESIMPULAN DAN SARAN}

\section{A. KESIMPULAN}

Berdasarkan karakteristik bangunan perdagangan dan jasa, moda transportasi dan lahan parkir adalah sebagai berikut. Pada bagian perdagangan barang yang dijual masih banyak dilakukan secara eceran daripada grosir, selanjutnya barang yang dibeli sebagian besar langsung dibeli oleh pembeli daripada diantar oleh pedagang. Bentuk tempat perdagangan masih didominasi oleh bentuk pertokoan, ruko, toko modern, warung toko dan pasar tradisional, dengan komoditas yang paling banyak diperjual belikan adalah primer. Pada bangunan jasa di Jalan Gajah Mada paling banyak berupa kategori tingkat keberwujudan. Selanjutnya moda transportasi yang paling banyak melewati Jalan Gajah Mada adalah kendaraan ringan dan motor. Ada tidaknya lahan parkir dan luasan lahan parkir di Jalan Gajah Mada ditentukan oleh seberapa luas bangunan yang berdiri yang mana pada bangunan yang memiliki lahan parkir kecil biasanya masih terdapat kendaraan yang memakai bahu jalan untuk dijadikan tempat parkir.

Hasil analisis menunjukan bahwa Jalan Gajah Mada memiliki nilai VCR yang bervariasi berkisar dari 0,1-0,3 dan LOS pada tiap segmen dari ketiga hari tersebut juga berada antara $\mathrm{A}$ dan B, yang artinya Jalan Gajah Mada masih aman dari kemacetan dan hanya terjadi hambatan kecepatan kendaran dikarenakan ada beberapa titik untuk melakukan putar arah dan terdapat beberapa akses untuk menuju Jalan Gajah Mada.

\section{B. SARAN}

Saran bagi pemerintah adalah kebutuhan parkir pada Jalan Gajah Mada harus diperhatikan. Karena masih terdapat beberapa kendaraan yang masih parkir pada bahu jalan dikarenakan kurangnya lahan parkir untuk beberapa kendaraan. Dengan lebar jalan yang sekarang saja kendaraan masih bisa terhambat dikarenakan kurangnya lahan parkir dan terdapat beberapa titik untuk melakukan putar arah yang dapat menyebabkan kendaraan terhenti sejenak jika yang memutar arah adalah mobil atau truck. Oleh karena itu, dapat dilakukan penambahan lebar jalan untuk menghindari hal tersebut. Untuk masyarakat dapat lebih tertib dalam berlalu 
lintas dan tidak parkir kendaraan sembarangan. Serta lebih dapat mematuhi rambu - rambu lalu lintas yang ada di koridor Jalan Gajah Mada.

\section{DAFTAR PUSTAKA}

Direktorat Jenderal Bina Marga. (1997). Manual Kapasitas Jalan Indonesia. Jakarta: Departemen Pekerjaan Umum.

Pedoman Perencanaan dan Pengoperasian Fasilitas Parkir. (1998). Jakarta: Direktorat Bina Sistem Lalu Lintas dan Angkutan Kota Direktorat Jenderal Perhubungan Barat.

Pemerintah Daerah Kota Pontianak. (2013). Peraturan Daerah Kota Pontianak Nomor 2 Tahun 2013 Tentang Rencana Tata Ruang Wilayah Kota Pontianak Tahun 2013-2033. Pontianak: Pemerintah Kota.

Sugiyono. (2016). Metode Penelitian Kuantitatif, Kualitatif dan R\&D. Bandung: PT. Alfabet. 